\title{
Ambient vibration measurements in the Southern Rhine Graben close to Basle
}

\author{
Andreas Köhler $\left({ }^{1}\right)$, Matthias Ohrnberger $\left({ }^{1}\right)$, Frank Scherbaum $\left({ }^{1}\right)$, Stefan Stange $\left(^{2}\right)$ \\ and Fortunat Kind $\left.{ }^{3}\right)\left({ }^{*}\right)$ \\ (') Institut für Geowissenschaften, Universität Potsdam, Germany \\ $\left({ }^{2}\right)$ Erdbebendienst des Landesamts für Geologie, Rohstoffe und Bergbau Baden-Württemberg (LGRB), \\ Freiburg im Breisgau, Germany \\ $\left(^{3}\right)$ Swiss Seismological Service, Eidgenössische Technische Hochschule Zürich, \\ Hönggerberg, Zürich, Switzerland
}

\begin{abstract}
This study presents results of ambient noise measurements from temporary single station and small-scale array deployments in the northeast of Basle. $H / V$ spectral ratios were determined along various profiles crossing the eastern masterfault of the Rhine Rift Valley and the adjacent sedimentary rift fills. The fundamental $H / V$ peak frequencies are decreasing along the profile towards the eastern direction being consistent with the dip of the tertiary sediments within the rift. Using existing empirical relationships between $H / V$ frequency peaks and the depth of the dominant seismic contrast, derived on basis of the $\lambda / 4$-resonance hypothesis and a power law depth dependence of the $S$-wave velocity, we obtain thicknesses of the rift fill from about $155 \mathrm{~m}$ in the west to $280 \mathrm{~m}$ in the east. This is in agreement with previous studies. The array analysis of the ambient noise wavefield yielded a stable dispersion relation consistent with Rayleigh wave propagation velocities. We conclude that a significant amount of surface waves is contained in the observed wavefield. The computed ellipticity for fundamental mode Rayleigh waves for the velocity depth models used for the estimation of the sediment thicknesses is in agreement with the observed $H / V$ spectra over a large frequency band.
\end{abstract}

Key words $H / V$ ratio - ambient vibration - array analysis - fundamental frequency - Rhine Rift Valley

\section{Introduction}

The Southern Rhine Rift Valley is among the most active seismic regions within Central Europe. Re-evaluation of the seismic hazard based on paleoseismological studies (MayerRosa and Cadiot, 1979; Meghraoui et al., 2001; Becker et al., 2002) showed that larger earth-

Mailing address: Dr. Matthias Ohrnberger, Institut für Geowissenschaften, Universität Potsdam, Karl-LiebknechtStr. 24, 14476 Golm b. Potsdam, Germany; e-mail: akoehler@rz.unipotsdam.de

${ }^{*}$ ) Now at: Converium Ltd., General Guisan Quai 26, CH-8022 Zürich, Switzerland. quakes such as the 1356 Basle event could be more frequent than previously thought. For the prediction of strong ground motion during potential future earthquakes, it is therefore of considerable interest to gain knowledge about wave propagation properties in the unconsolidated sediment layers.

In this study we present results from an ambient vibration measurement campaign for a region north-east to the city of Basle extending the work of Kind (2002) and Fäh et al. (1997). Kind presented $H / V$ results from microtremor recordings together with a geological model for the urban area of Basle. The geology of the measurement area outside of the city border of Basle must be seen as not verified due to lack of available data but can be extrapolated from the geological profiles shown in Kind's paper. Basle is situated within the Rhine Rift between 
the Allschwil fault zone and the eastern masterfault. Near the masterfault, the St. Jakob Tüllingen synclinal structure consisting of 100$400 \mathrm{~m}$ thick tertiary sediments forms the boundary of the rift fill.

The analysis of ambient seismic vibration recordings for site effect estimation is considered a low-cost alternative to expensive investigation methods such as drilling or active seismic experiments (Aki, 1957; Milana et al., 1996; Bard, 1998; Ohmachi and Umezono, 1998). It has become very popular to estimate the natural frequencies of soil columns from horizontal to vertical $(H / V)$ spectral ratios at single stations (Kudo, 1995; Bard, 1998). Furthermore, the array analysis of surface wave dispersion characteristics from ambient vibration data allows to derive shallow shear-wave velocity profiles (Aki, 1957; Lacoss et al., 1969; Asten and Henstridge, 1984; Horike, 1985; Tokimatsu, 1997).

Nakamura and Ueno (1986) and Nakamura (1989, 2000) suggested that taking the $H / V$ ratio reduces the effect of the source, and thus the spectral ratio represents the stationary amplification function of the soft rock due to «shear wave resonance» ( $\lambda / 4$-hypothesis). The condition for this interpretation is that the wavefield contains a significant portion of body waves and that there is a sufficiently high impedance contrast between sediment layer and underlying bedrock. Under the assumption that these conditions are met, empirical correlations between sediment layer thicknesses $h$ and peak frequencies $f_{0}$ can be determined, if independent information about sediment bedrock interface depths is available.

On the basis of phase velocity analysis results from microtremor array measurements (Asten and Henstridge, 1984; Tokimatsu and Miyadera, 1992) many authors argued, in contrast to Nakamura's interpretation of the $H / V$ ratio, that the ambient vibration wavefield is often dominated by surface waves (Lachet and Bard, 1994; Fäh et al., 2001; Cornou and Bard, 2003; Scherbaum et al., 2003). Assuming that a significant portion of the wavefield is due to the propagation of fundamental mode Rayleigh waves, the fundamental peak in the $H / V$ ratio can be explained as an effect of the frequency dependence of the ellipticity of Rayleigh waves as a response to the site structure.

In general, the peak frequencies of Rayleigh wave ellipticities $\left(f_{\text {ell }}\right)$ differ from those caused by $S H$-resonance effects $\left(f_{S H}\right)$. A quantitative characterization of this problem was given recently by Malischewsky and Scherbaum (2004) for a simple single layer over halfspace model. The ratio $f_{\text {ell }} / f_{S H}$ varies from 0.5 to 1.5 for $S$ wave velocity contrasts below 3.5. For $S$-wave velocity contrasts above 3.5 , however, the peak frequencies $f_{\text {ell }}$ and $f_{S H}$ match closely.

\section{Measurement and data}

In April 2002, the Institute of Geosciences of the University of Potsdam, the Landesamt für Geologie, Rohstoffe und Bergbau (LGRB) and the ETH in Zürich carried out a field experiment in the area around Weil and Lörach using a homogeneous set of Lennartz LE3D-5s sensors connected to MarsLite stations with GPS timing and Mars88 station with DCF77 time receivers.

Two dense array configurations (A, B) were realized, consisting of 22 (A) and 21 (B) sensors with an aperture of about $900 \mathrm{~m}$ and 600 $\mathrm{m}$, respectively. The site of these measurements was located at the southern border of the city of Weil, close to the location of a deep drillsite in Otterbach (fig. 1). The total recording time (continuous mode) was 4 to $5 \mathrm{~h}$ for each array setting. The sampling rate $f_{S}$ was set to $125 \mathrm{~Hz}$.

In addition, single station measurements were performed along profiles as shown in fig. 1. In the western part of the profile, measurements started at the Rhine River. Towards eastern direction, crossing the city of Weil in the north of the array sites, the profile traversed a topographic height, the «Tüllinger Berg». From there, the profiles extend through the city center of Lörrach in northern and eastern directions, crossing the eastern masterfault of the Rhine Rift Valley.

The average station distance in between the 108 individual measurement points was around $100 \mathrm{~m}$ along the profile. The recording time (continuous mode) for each site was about 30 min each $\left(\right.$ at $f_{S}=62.5 \mathrm{~Hz}$ ). 


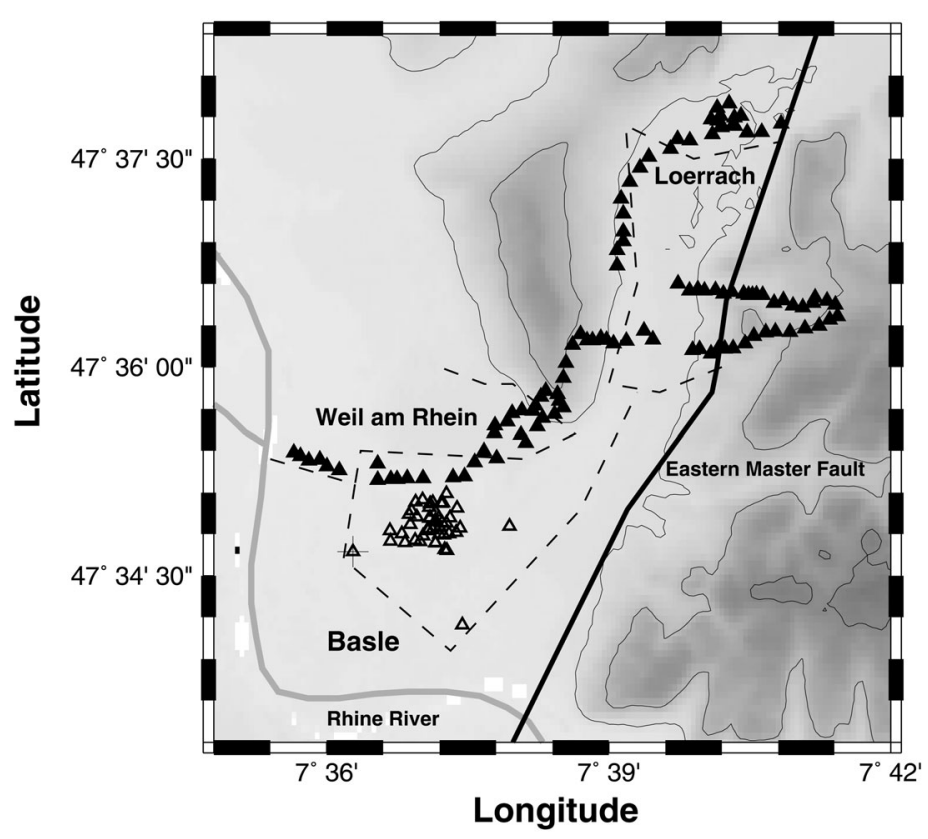

Fig. 1. Location of the single station measurements (filled triangles) and array settings (open triangles) in the study area in the Rhine Rift Valley near Basle. The dashed lines indicate the city borders and the cross shows the location of the deep drillsite in Otterbach.

All measurements were carried out during working hours at day time.

\section{Analysis of $H / V$ spectral ratios}

In accordance to the recommendations described in Bard's review paper (1998), summarizing the experiences of different authors with respect to $H / V$ processing, we selected transientfree time windows for further analysis. Time window selection was performed visually and the resulting time windows had lengths of 3 to $10 \mathrm{~min}$. For the single station $H / V$ analysis along the profile, two independent data windows were used for the processing, while 3 to 7 data windows were selected from the array measurement data.

For the computation of $H / V$ spectral ratios, we removed the overall mean from the individual records in a preprocessing step. We calculated the single component amplitude spectra for overlapping segments using a standard FFT algorithm. The selected segment length of 2048 FFT points at a sample rate of $62.5 \mathrm{~Hz}(125 \mathrm{~Hz}$ for array stations) corresponds to a frequency resolution of $0.0305 \mathrm{~Hz}(0.061 \mathrm{~Hz})$. The spectra were smoothed by a logarithmic shaped taper window as introduced by Konno and Ohmachi (1998) (bandwidth parameter $b=30$ ) and the $H / V$ spectral ratio was computed for each segment. For the horizontal component $(H)$ in the $H / V$ spectral ratio computation, we combined the individual horizontal component spectra of $N$ and $E$ by using the geometric mean $(H=\sqrt{N E}$ : Tokimatsu, 1997). Finally, we calculated the mean and variances of the $H / V$ ratios from all segments under the assumption of a log-normal distributed amplitude spectra. Depending on the window length 10 to 56 segments were used for averaging.

For further quantitative interpretation of the fundamental $H / V$ peak frequencies, we intro- 

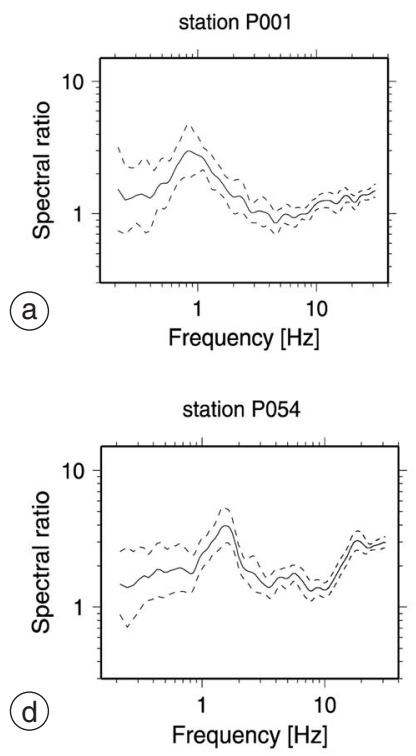
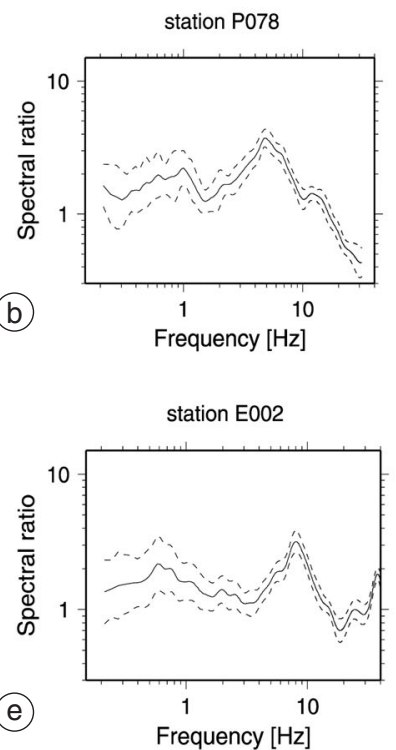
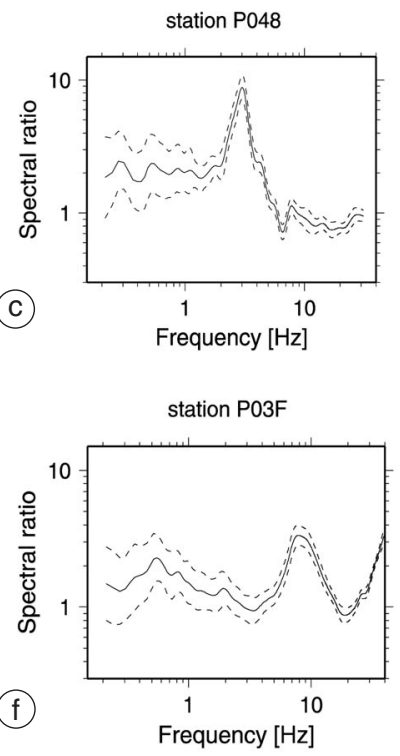

Fig. 2a-f. Averaged spectral $H / V$ ratios for representative stations; fundamental frequency peak lower than 1 $\mathrm{Hz}$ (a), higher than $1 \mathrm{~Hz}$ (b, c, d), lower than $1 \mathrm{~Hz}$ and secondary peak (e, f). The dashed lines indicate the uncertainty estimate as one standard deviation.

duced consistent criteria for the visual determination of $H / V$ peaks. We considered only peaks within a frequency band from 0.3 to10 Hz. The lower frequency limit was chosen to stay away from inevitable long-period disturbances of the data caused by instrumental effects (stabilizing time of the feedback sensor electronics) in rapid mobile experiment setups or weather conditions (Cara et al., 2003). The upper limit was specified due to the temporal instability and physical limit for a sensible interpretation of $H / V$ ratios within the context of site effect characterization for peak frequencies above $10-20 \mathrm{~Hz}$.

To select the peak frequencies, a $\log / \log$ diagram was chosen. Shown in fig. 2a-f are six typical $H / V$ ratio examples averaged from the $H / V$ spectra of all processed recordings being representative for particular profile segments. Only the first (lowest frequency) peak was analysed. It was checked if the same peak was identified consistently in the $H / V$ spectra of all available recordings for the site before averaging.

Analysing all sites along the profile (108) and the individual array stations (43) we found clear $H / V$ spectral ratio peaks meeting our criteria defined above for 82 sites. From these spectra we determined fundamental peak frequencies between 0.5 to $0.9 \mathrm{~Hz}$ for sites lying in the western profile part from the Rhine River to the city of Weil including the two arrays located south of Weil. At some of those sites, especially at the stations from the array deployments, secondary peaks between 7 to $10 \mathrm{~Hz}$ were found and documented. This observation is supported by the results of Kind (2002) for his sites more southernly.

Within the urban center of Weil only one spectral ratio fulfilled our criteria. Several peaks could be identified for the profile part crossing the «Tüllinger Berg» between Weil and Lörrach showing intermediate frequencies between 3.5 to $8 \mathrm{~Hz}$. Again, no peaks were identified within the urban center of Lörrach, but well resolved spectral peaks ranging from 1 to $10 \mathrm{~Hz}$ appeared in the adjacent areas to the east and north of Lörrach. Figure 3 summarizes the spatial distribution of all determined fundamental peak frequencies. Considering the geological model 


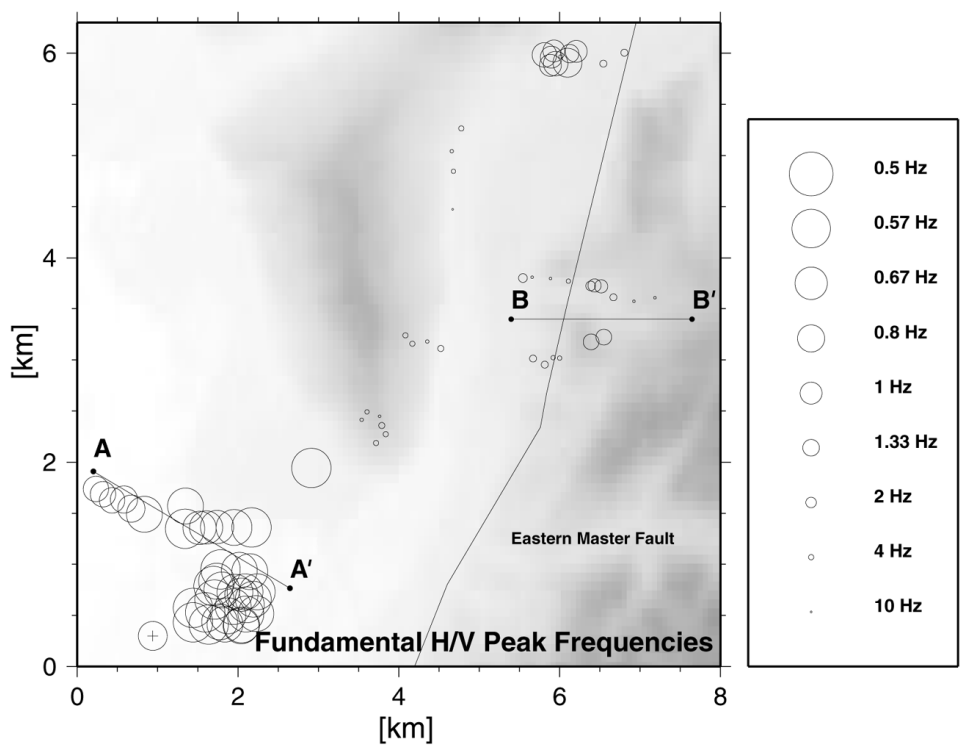

Fig. 3. Fundamental peak $H / V$ frequencies found in the study area, location of profile $\mathrm{A}-\mathrm{A}^{\prime}$ and $\mathrm{B}-\mathrm{B}^{\prime}$ (see fig. 4) and the position of the eastern masterfault of the Rhine Rift Valley. The cross indicates the location of the deep drillsite in Otterbach.
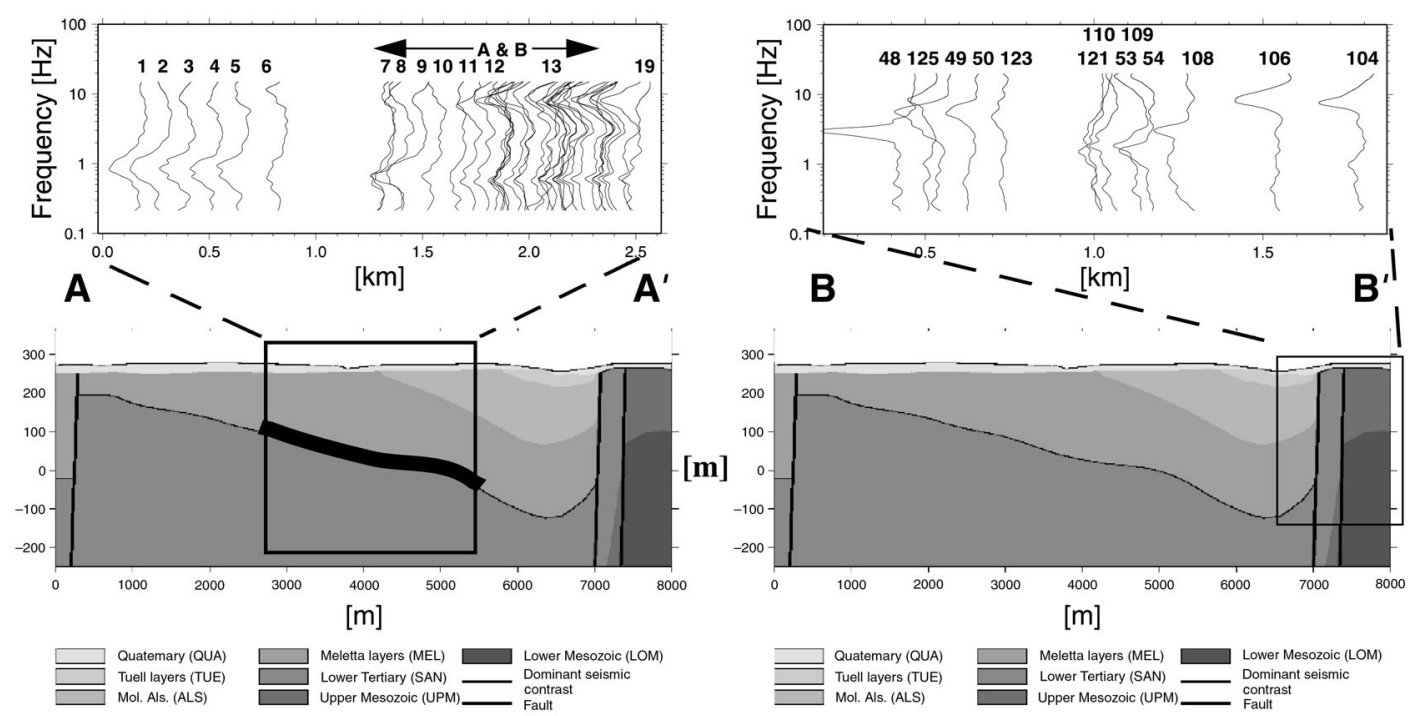

Fig. 4. Spatial evolution of spectral $H / V$ ratios along profile $\mathrm{A}-\mathrm{A}^{\prime}$ (profile stations and stations from array A and $\mathrm{B}$ ) and $\mathrm{B}-\mathrm{B}^{\prime}$. The averaged $H / V$ spectral ratios were plotted for each individual site where the abscissa of the diagrams corresponds to the relative distances between the stations projected onto the profile axis. The geological profile was modified after Kind (2002). The length and position of the boxes in the profile show the approximate $H / V$ measurement locations. 
(Kind, 2002) it turned out that the distribution of peak frequencies apparently correlates well with the variation of the thickness of the sediment fill within the western part of the study area.

In order to allow the identification of the spatial relation between the fundamental peak frequencies, we created fig. 4, showing averaged $H / V$ spectral ratios for two profile segments $\mathrm{A}-\mathrm{A}^{\prime}$ and $\mathrm{B}-\mathrm{B}^{\prime}$ as indicated in fig. 3. The $H / V$ spectral ratios were plotted together with their relative position with respect to the geological profile after Kind (2002).

\section{4. $F K$ analysis of array data}

The use of array analysis methods allows us to decompose the ambient noise wavefield and to derive frequency dependent phase velocities of individual wavefield components. In particular, it is possible to derive the dispersion properties of the surface wave contribution at a particular site. This allows us to invert for shallow $S$-wave velocity structures (Horike, 1985; Herrmann, 1987; Malagnini et al., 1995; Tokimatsu, 1997; Scherbaum et al., 2003; Wathelet et al., 2004).

For the analysis we selected the vertical component data of the same time windows as have been used previously for the determination of $H / V$ ratios at the array station locations. As stations with both GPS timing and DCF77 time receivers had been used in the experiment it was necessary to apply a time shift correction for the DCF77 receivers before computing the $F K$ spectra. The time shift delays were determined by crosscorrelation techniques during a laboratory experiment (Kind et al., 2002).

We applied two different $F K$ methods for the estimation of the wavefield properties. First we computed conventional $F K$ spectra in a sliding window analysis for narrow frequency bands. The dispersion curve information was then derived by averaging the slowness values obtained from the peak location for each single analysis window as well as by visualizing the histogram statistics as shown in fig. 5a,b. Beside the mean
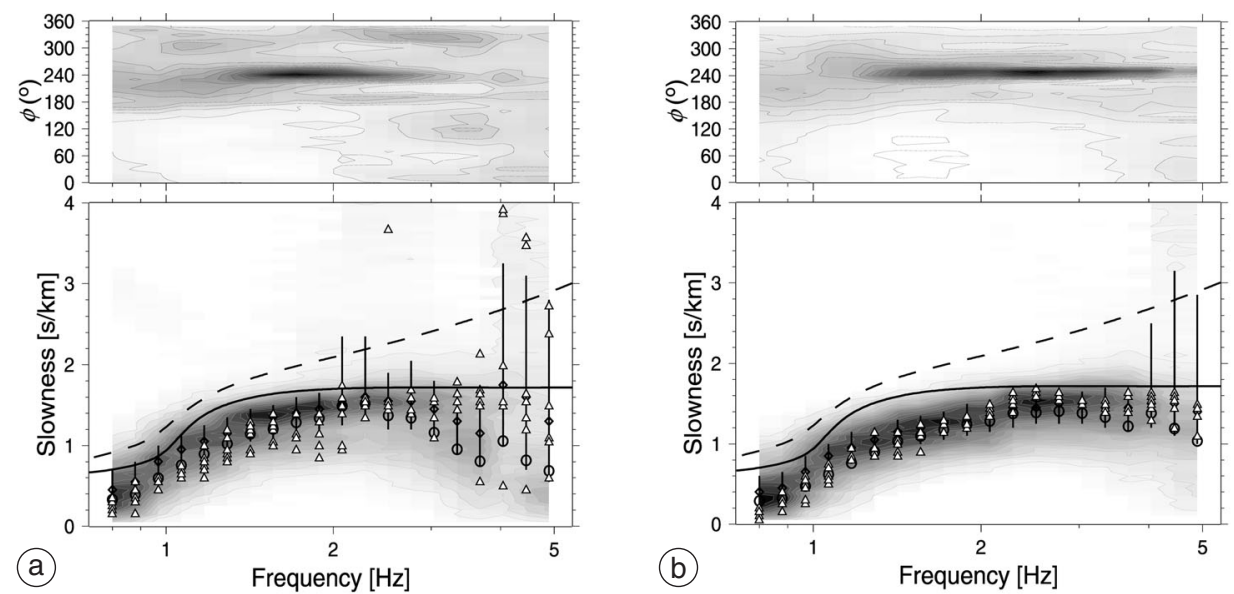

Fig. 5a,b. Source azimuth and dispersion curve of array A (a) and B (b). The results of the FK methods are shown in a histogram-contour plot of slowness maxima for each frequency taken from the FK spectra of individual analysis windows. The median (black diamond with the $75 \%$ and $25 \%$ quantile as given by the error bars) and mean (black circle) are plotted. The white triangles are the slowness estimates calculated by Capon's method. The black curves represent the dispersion curve of the site obtained by forward calculation. The solid one was determined from the geological model after Kind (2002) and the dashed one was calculated based on the power law velocity depth distribution. 
value (black circle) we computed the median (black diamond) and the 25\% and $75 \%$ quantiles (represented by black error bars) of the overall distribution. Additionally, we used Capon's high resolution method (1969) for single target frequencies and, following the underlying assumption of wavefield stationarity, used the block-averaging technique proposed in Capon's original work for stabilization. As result we obtained a single slowness estimate for each target frequency (white triangles in fig. 5a,b).

In fig. 5a,b we observe a clear dispersion relation in the frequency band between 0.8 and 2 $\mathrm{Hz}$ allowing the conclusion that a considerable part of the wavefield is composed of Rayleigh waves. Above $2 \mathrm{~Hz}$, significant alias effects are recognized indicating that the spatial sampling of the array settings were insufficient for the corresponding wavelength-ranges. In the upper panel of fig. 5a,b, we show the directional distribution of the $F K$ results. For the temporary array deployments, we observed a rather narrow source azimuth region at around $240^{\circ}$ corresponding to the direction of the railway station in Basle.

\section{Discussion and conclusions}

In order to allow a quantitative interpretation of the relation between peak frequency and sediment thickness cover, we derived a depth estimate from the measured $H / V$ peak frequencies. Assuming that the origin of the $H / V$ spectral ratio fundamental peak is related to $S$-wave resonances in a single sediment layer over halfspace $(\lambda / 4$-hypothesis for shear waves: Nakamura, 1989), the layer thickness $h$ can be related to the $H / V$ fundamental peak frequency $f$ as

$$
f=\frac{n v_{s}}{4 h}
$$

where $n$ are uneven integers $n=1,3,5$, and $v_{s}$ is the shear wave velocity of the sediment layer.

In sedimentary basins, the depth-dependence of the $S$-wave velocity can often be described by a power law relation of the form $v_{s}(Z)=v_{s 0}(1+Z)^{x}$ (Budny, 1984). Here, $Z$ is the depth, $v_{s 0}$ the $S$-wave velocity at the surface and $x$ the exponent of the power-law relation. Then, by integrating the velocity function with fixed parameters $v_{s 0}$ and $x$ over the depth range from surface to the depth of the seismic contrast $h$, it is possible to derive a modified relation between $H / V$ peak frequency $f$ and $h$ of the form

$$
h=a f_{H / V}^{b} .
$$

This relation can be used to obtain parameters $a$ and $b$ (related to $v_{s 0}$ and $x$ ) empirically by fitting data sets of $H / V$ frequencies $f$ at sites where independent information about the sediment thickness $h$ is available (e.g., borehole data).

Lacking accurate depth information for our study region, we used relation (5.1) to determine the depth of the main seismic contrast from the observed peak frequencies using empirical estimates of $a$ and $b$ derived for the Lower Rhine Embayment (LRE) in NW-Germany by Ibs van Seht and Wohlenberg (1999), Parolai et al. (2002) and recently by Hinzen et al. (2004). The parameters $a$ and $b$ found by these authors are given in table I. Finally, we compared the depth estimates with the geological model after Kind (2002; details are given in table II).

Along the profile $A-A^{\prime}$, as shown in fig. 6, we found that the values specified by Hinzen $e t$ al. (2004) are in very good agreement with the geological model. Both the depth and the dip of this seismic contrast is in good correspondance to the lithological boundary described in Kind (2002) between the Oligocene Meletta Layers and the lower Tertiary unit forming the St. Jakob Tüllingen synclinal structure in the Basle area. From west to east the estimated depths of the interface increase from $155 \mathrm{~m}$ to $280 \mathrm{~m}$.

Table I. Different model parameters for the empirical relation between peak frequency and depth of the dominant seismic contrast.

\begin{tabular}{lcc}
\hline \hline Study & $a$ & $b$ \\
\hline Ibs van Seht and & 96 & -1.388 \\
Wohlenberg (1999) & & \\
Parolai et al. (2002) & 108 & -1.551 \\
Hinzen et al. (2003) & 137 & -1.190 \\
\hline
\end{tabular}


Table II. Depth and velocity models for location A (P001) and A' (P019). The models for P019 and the array site are identical.

\begin{tabular}{|c|c|c|c|c|c|c|}
\hline & \multicolumn{3}{|c|}{ Model 1} & \multicolumn{3}{|c|}{ Model 2} \\
\hline & $\begin{array}{l}\text { Layer thickness } \\
\text { after Kind (2002) }\end{array}$ & $\begin{array}{c}v_{s} \text { model } \\
\text { after Kind (2002) }\end{array}$ & Avg. $v_{s}$ & $\begin{array}{l}\text { Layer thickness } \\
\text { derived from } f_{H / V}\end{array}$ & $\begin{array}{l}v_{s} \text { power } \\
\text { law model }\end{array}$ & Avg. $v_{s}$ \\
\hline \multirow[t]{4}{*}{ P001 } & $10 \mathrm{~m}$ & $450 \mathrm{~m} / \mathrm{s}$ & $590 \mathrm{~m} / \mathrm{s}$ & $155 \mathrm{~m}$ & $\begin{array}{c}\text { Power law: } x=0.225 \\
v_{s 0}=215.5 \mathrm{~m} / \mathrm{s} \\
\text { (Hinzen } \text { et al., 2003) }\end{array}$ & $534 \mathrm{~m} / \mathrm{s}$ \\
\hline & - & - & & & & \\
\hline & $165 \mathrm{~m}$ & $600 \mathrm{~m} / \mathrm{s}$ & & & & \\
\hline & halfspace & $2000 \mathrm{~m} / \mathrm{s}$ & $2000 \mathrm{~m} / \mathrm{s}$ & halfspace & $2000 \mathrm{~m} / \mathrm{s}$ & $2000 \mathrm{~m} / \mathrm{s}$ \\
\hline \multirow[t]{4}{*}{ P019 } & $10 \mathrm{~m}$ & $450 \mathrm{~m} / \mathrm{s}$ & $607 \mathrm{~m} / \mathrm{s}$ & $280 \mathrm{~m}$ & $\begin{array}{c}\text { Power law: } x=0.225 \\
v_{s 0}=215.5 \mathrm{~m} / \mathrm{s} \\
\text { (Hinzen } \text { et al., 2003) }\end{array}$ & $595 \mathrm{~m} / \mathrm{s}$ \\
\hline & $70 \mathrm{~m}$ & $650 \mathrm{~m} / \mathrm{s}$ & & & & \\
\hline & $200 \mathrm{~m}$ & $600 \mathrm{~m} / \mathrm{s}$ & & & & \\
\hline & halfspace & $2000 \mathrm{~m} / \mathrm{s}$ & $2000 \mathrm{~m} / \mathrm{s}$ & halfspace & $2000 \mathrm{~m} / \mathrm{s}$ & $2000 \mathrm{~m} / \mathrm{s}$ \\
\hline
\end{tabular}

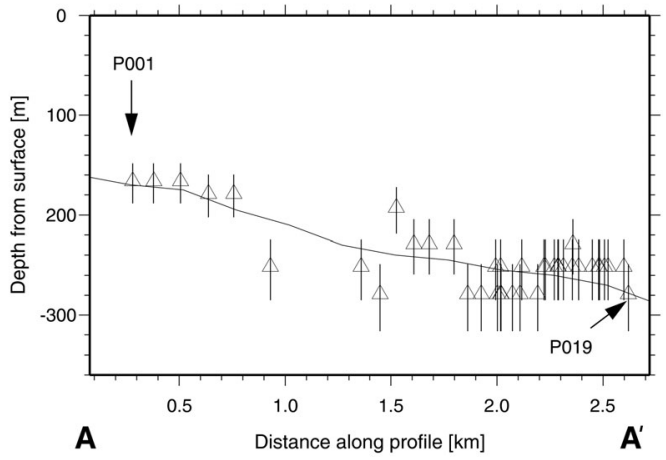

Fig. 6. Calculated interface depths (black triangles) $h$ from fundamental peak frequencies $f_{0}(10 \%$ uncertainty: black error bars) after Hinzen et al. (2003) based on the «shear wave resonance» and a power law velocity depth distribution leading to an empirical relation of the form: $h=a f_{H I V}^{b}$. The solid line represents the depth of the dominant seismic contrast after Kind (2002) for profile A-A' (P001-P019).

Using the alternative power-law depth models given by Ibs van Seht and Wohlenberg (1999) and Parolai et al. (2002), the depth estimates (110-220 m and 130-270 m, respectively) seem to be too shallow considering the geological background information. A more detailed comparison between the individual studies is discussed by Hinzen et al. (2004).

We further observed clear secondary peaks at higher frequencies around 7 to $10 \mathrm{~Hz}$ along the profile $\mathrm{A}-\mathrm{A}^{\prime}$, which convert to interface depths of $9 \mathrm{~m}$ to $14 \mathrm{~m}$. These shallow layers can be attributed to the Quaternary low velocity layers overlaying the tertiary sediments, as suggested by Kind (2002) and recently validated by results of $S$-wave seismic experiments (U. Polom, pers. comm.).

For the eastern part of the $H / V$ profile (see B-B' in fig. 4b) the relation between the geological structure and the depth estimates from $H / V$ frequency peaks is apparently more complicated. A first order interpretation allows us to divide the results in three major regions. To the West of and above the eastern masterfault, as supported by the geological model, a shallow inclined structure dipping towards western direction is hypothesized. However, to the East of the fault, due to the existence of parallel «subfaults» and probably complicated geologic patterns, no systematic spatial correlation between the $H / V$ ratios is observed along the profile in 
eastern direction. Finally, to the East of the fault zone two dominant peaks at high frequencies around $8 \mathrm{~Hz}$ suggest the existence of a shallow dominant seismic contrast, which was also recently validated by the $S$-wave seismic experiments (U. Polom, pers. comm.).

Considering the observed dominant energy contribution of Rayleigh waves in the wavefield derived from the array measurements we tested additionally whether the observed peak frequencies are in accordance with the Rayleigh wave ellipticity assumption and the velocity structure. Therefore we computed fundamental mode Rayleigh wave dispersion curves and ellipticities (Herrmann, 1987) for the two outermost stations (P001, P019) from the profile section A-A' using two types of velocity models (table II). The first model (model 1) is based on the velocity model given by Kind (2002), with interface depths approximated from the geological model. The alternative model (model 2) is an approximation of the power-law distribution by a stack of thin layers over bedrock, where the parameters $a$ and $b$ are selected according to
Hinzen et al. (2004). In both models the bedrock depth was set to the previously determined value from the $H / V$ fundamental peak frequencies at the station locations. For the bedrock velocity we used the value given by Kind (2002). The models parameters are summarized in table II.

In fig. 7a-d we superposed the observed $H / V$ spectral ratios and the theoretical Rayleigh wave ellipticities (absolute value). We find that all computed peak frequencies of the ellipticity curves for both models and stations overestimate the observed fundamental peak frequencies. The relative peak frequency mismatch ranges from $10 \%$ to $30 \%$, depending on velocity model assumption and station. However, for station P019 (fig. 7b) we observe remarkably similar broadband shapes for the ellipticity curve and the $H / V$ ratio for the power-law velocity depth model (model 2).

Considering the results of Malischewsky and Scherbaum (2004) who demonstrated the strong dependence of the ratio between $f_{S H}$ and $f_{\text {ell }}$ on the velocity contrast in a single layer over
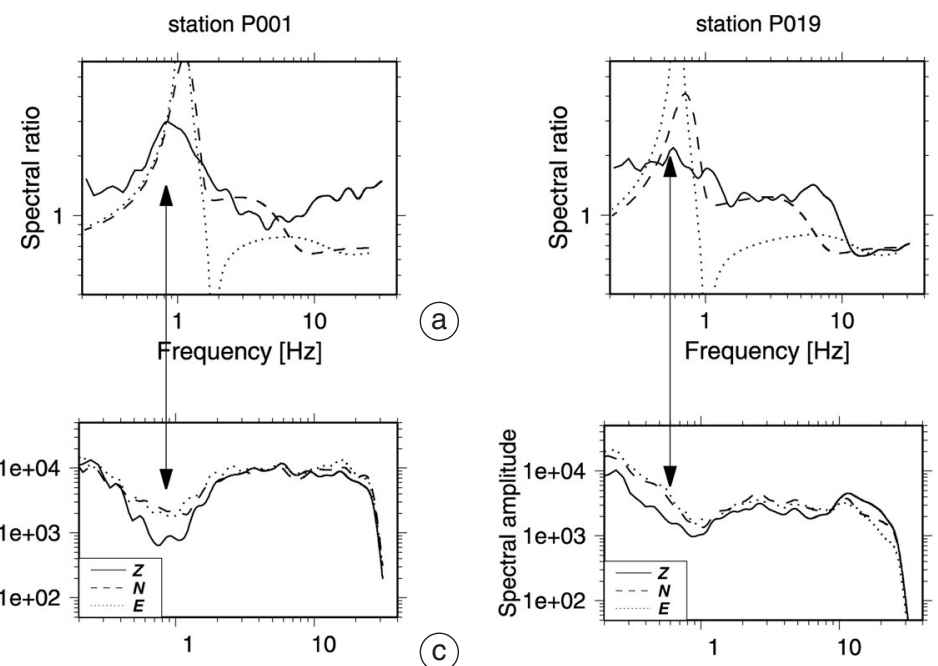

(b)

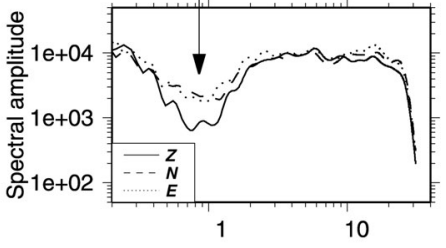

(C)

Fig. 7a-d. Measured $H / V$ ratio (solid line) and theoretical ellipticities for station P001 (a) and P019 (b). The ellipticities were determined for the power-law model (dashed line) of Hinzen et al. (2003) and a three-layer over halfspace model (dotted line) after Kind (2002). Model parameters are found in table II. Additionally, the individual component spectra $(E, N, Z)$ for both stations are plotted (c and d). The vertical arrows point to the $\mathrm{H} / \mathrm{V}$ peak frequencies in panels (a) and (b) and relate those to the individual component spectra in panels (c) and (d). 
halfspace situation, the discrepancies of peak frequencies could be explained by shear wave velocity contrasts in the range of 2.5 to 3.5 . Using the model parameters from table II, we derive velocity contrasts ranging from 2.6 to 3.35 . Interestingly, although the velocity models used are more complicated in our case, this value range is consistent with the theoretically derived statement made in Malischewsky and Scherbaum (2004).

Due to the lack of independent information on the interface depth, the question regarding the physical cause of the observed fundamental frequencies $f_{0}$ remains ambiguous. In favour of the $f_{S H}$ hypothesis is the fact, that for station P019, both the power law model and the constant model after Kind (2002) reproduce the observed fundamental peak frequency and independently show the same sediment layer depth. In favour of the Rayleigh wave hypothesis are the results of the dispersion analysis from the array measurements and the spectral shape of the individual component spectra as shown in fig. $7 \mathrm{c}, \mathrm{d}$. There we recognize a trough in the vertical component spectrum around the frequency of the observed fundamental $H / V$ peak. The horizontal components do not show any amplification at these frequencies as would be suggested from the alternative interpretation as a resonance effect $\left(f_{S H}\right)$.

Most likely we observe some mixed contribution from both resonance and ellipticity effects. Although, at present, we cannot validate this hypothesis, we want to point out the consequences for a possible misinterpretation of fundamental peak frequencies from ambient noise $H / V$ measurements. Without knowing the physical cause of the observed fundamental peak frequency $f_{0}$, we would interpret this frequency as the dominant frequency of site amplification during strong ground motion. However, for the case of observing $f_{\text {ell }}$ at a site with weak impedance contrast, the energetically most important frequency of site amplification during strong ground motion $-f_{S H}-$ would differ significantly from our estimate.

Beside the possible mismatch of fundamental resonance frequencies for certain impedance contrasts and its implications for hazard related site effect studies, the question to what degree $f_{0}$ measured from $H / V$ spectral ratios is controlled by resonance of body waves $f_{S H}$ or by Rayleigh wave ellipticities $f_{\text {ell }}$ contains another important consequence. Given that $f_{0}$ is related to $f_{S H}$, we could interpret the amplitude of the resonance peak as an estimate of the amplification factor for moderate to strong motion (as long as nonlinear effects are not concerned). However, if $f_{\text {ell }}$ is the physical cause of $f_{0}$, the peak amplitude would carry no direct relation to the site amplification factors, as the amplitude solely depends on the relative $P-S V$ energy partioning on horizontal and vertical components.

In order to obtain further insight into this problem, we need quantitative estimates of the energy partitioning between body and surface waves in the ambient vibration wavefield. This makes it necessary to use densely deployed three component array measurements to reliably distinguish the individual wavefield components one from another.

\section{Acknowledgements}

We thank all participants in the field work, especially W. Brüstle, C. Cornou, A. Kristen, J. Woessner, J. Kirsch and the administrative staff of the LGRB. Our special thank goes to D. Vollmer for his continuous efforts in station maintenance, technical improvements and field participation. This work was realised within the scope of the SESAME-project (EU-Grant No. EVG1-CT-2000-00026 SESAME); M. Ohrnberger was funded by SESAME.

\section{REFERENCES}

AKI, K. (1957): Space and time spectra of stationary stochastic waves, with special reference to microtremors, Bull. Earthquake Res. Inst., Tokyo Univ., 35, 415-457.

Asten, M.W. and J.D. HenstRidge (1984): Array estimators and the use of microseisms for reconnaissance of sedimentary basins, Geophysics, 49 (11), 1828-1837.

BARD, P.Y. (1998): Microtremor measurements: a tool for site effect estimation?, in Second Int. Symposium on the Effects of Surface Geology on Seismic Motion, 3, 12511279 .

Becker, A., C.A. DavenPort and D. Giardini (2002): Palaeoseismicity studies on end-Pleistocene and Holocene lake deposits around Basle, Switzerland, Geophys. J. Int., 149, 659-678. 
Budny, M. (1984): Seismische Bestimmung der Bodendynamischen Kennwerte von oberflächennahen Schichten in Erdbebengebieten der niederheinischen Bucht und ihre ingenieurseismologische Anwendung, PhD Thesis, Geological Institute of the University of Cologne, Spec. Publ. 57, pp. 208.

CAPON, J. (1969): High-resolution frequency-wavenumber spectrum analysis, Proc. IEEE, 57 (8), 1408-1418.

Cara, F., G. Di Giulio and A. Rovelli (2003): A study on seismic noise variations at Colfiorito, Central Italy: implications for the use of $H / V$ spectral ratios, Geophys. Res. Lett., 30 (18), 1972, doi:10.1029/2003GL017807.

CORNOU, C and P.Y BARD (2003): Site-to-bedrock over 1D transfer function ratio: An indicator of the proportion of edge-generated surface waves?, Geophys. Res. Lett. 30 (9), 1453, doi:10.1029/2002GL016593.

FÄH, D., E. RÜTTENER, T. NOACK and P. KRUSPAN (1997): Microzonation of the City of Basel, J. Seismol., 1, 87102.

FÄH, D., F. KIND and D. GIARDINI (2001): A theoretical investigation of average $H / V$ ratios, Geophys. J. Int., 145 , 535-549.

Hermann, R.B. (1987): Computer Programs in Seismology (St. Louis University, Missouri).

Hinzen, K.G., F. Scherbaum and B. Weber (2004): On the resolution of $H / V$ measurements to determine sediment thickness, a case study across a normal fault in the Lower Rhine Embayment, Germany, J. Earthquake Eng., 8 (6), 909-926.

HORIKE, M. (1985): Inversion of phase velocity of long-period microtremors to the $S$-wave-velocity structure down to the basement in urbanized areas, J. Phys. Earth, 33, 59-96.

IBS VAN SEHT, M. and J. WoHLENBERG (1999): Microtremor measurements used to map thickness of soft soil sediments, Bull. Seismol. Soc. Am., 89, 250-259.

KIND, F. (2002): Development of microzonation methods: application to Basle, Switzerland, Ph.D. Thesis (Swiss Federal Institute of Technology Zürich), Dissertation No. 14548, ETH Zürich.

KInd, F., M. Grieder, C. BÄrlocher and P. ZweIFel (2002): Timing differences of Mars88 DCF77 time synchronisation, Int. Rep. ETH Zürich.

KonNo, K. and T. OHMACHI (1998): Ground-motion characteristics estimated from spectral ratio between horizontal and vertical components of microtremor, Bull. Seismol. Soc. Am., 88 (1), 228-241

Kudo, K. (1995): Practical estimates of site response, in Proc. 5th Int. Conf. on Seismic Zonation, Nice, France, 1878-1907.

LACHET, C. and P.Y. BARD (1994): Numerical and theoretical investigations on the possibilities and limitations of Nakamura technique, J. Phys. Earth, 42 (5), 377-397.

LACOSS, R.T., E.J. KELLY and M.N. ToKsÖZ (1969): Estimation of seismic noise structure using arrays, Geophysics, 34, 21-38.

Malagnini, L., R.B. Herrmann, G. Biella and R. DE FRANCO (1995): Rayleigh waves in quaternary alluvi- um from explosive sources: determination of shear wave velocity and $Q$ structure, Bull. Seismol. Soc. Am., 85, 900-922.

MalischewsKy, P.G. and F. SCHERbaum (2004): Love's formula and $H / V$-ratio (ellipticity) of Rayleigh waves, Wave Motion, 40, 57-67.

Mayer-RosA, D. and B. CADIOT (1979): A review of the 1356 Basel earthquake, Tectonophysics, 53, 325-333.

Meghraoui, M., B. Delouis, M. Ferry, D. Giardini, P. Huggenberger, I. SpottKe and M. Granet (2001): Active normal faulting in the upper Rhine Graben and paleoseismic identification of the 1356 Basel earthquake, Science, 293, 2070-2073.

Milana, G., S. Barba, E. Del Pezzo and E. Zambonelli (1996): Site response from ambient noise measurements: new perspectives from an array study in Central Italy, Bull. Seismol. Soc. Am., 86, 320-328

NAKAMURA, Y. (1989): A method for dynamic characteristic estimation of subsurface using microtremors on the ground surface, Q. Rep. Railw. Tech. Res. Inst. Tokyo, 30 (1), 25-33.

NAKAMURA, Y. (2000): Clear identification of fundamental idea of Nakamura's technique and its applications, in Proceedings of the XII World Conference Earthquake Engineering, New Zealand, Pap. no. 2656.

NAKAMURA, Y. and N. Ueno (1986): A simple estimation method of dynamic characteristics of subsoil, in Proceedings of the 7th Japan Earthquake Engineering Symposium, 265-270 (in Japanese).

OHMACHI, T. and T. UMEZONo (1998): Rate of Rayleigh waves in microtremors, in Second Int. Symposium on the Effects of Surface Geology on Seismic Motion, 2, 587-592.

Parolai, S., P. Bormann and C. Milkereit (2002): New relationships between $V_{s}$, thickness of sediments, and resonance frequency calculated by the $H / V$ ratio of seismic noise for Cologne Area (Germany), Bull. Seismol. Soc. Am., 92 (6), 2521-2527.

Scherbaum, F., K. Hinzen and M. Ohrnberger (2003): Determination of shallow shear wave velocity profiles in the Cologne, Germany area using ambient vibrations, Geophys. J. Int., 152, 597-612

TOKIMATSU, K. (1997): Geotechnical site characterization using surface waves, in Earthquake Geotechnical Engineering, edited by K. Ishihara (Balkema Press, Rotterdam), 1333-1367.

TOKIMATSU, K. and Y. MiYADERA (1992): Characteristics of Rayleigh waves in microtremors and their relation to shear structures, J. Struct. Construct. Eng., AIJ, 439, 81-87 (in Japanese).

Wathelet, M., D. Jongmans and M. OHRnberger (2004): Surface wave inversion using a direct search algorithm and its application to ambient vibration measurements, Near Surf. Geophys., 2 (4), 211-221.

(received January 9, 2004; accepted July 27, 2004) 